\title{
Chapter 14 \\ The Decisions of Wannabe Dog Keepers in the Netherlands
}

\author{
Susan Ophorst and Bernice Bovenkerk
}

\begin{abstract}
Dogs have for long been humans' best friend, but the human-dog relationship can be problematic. A mismatch between dogs and their keepers can lead to welfare problems for both; for example: breeding for a specific look can result in health and welfare problems and importing dogs from other countries can lead to zoonoses. In our view, many of these problems could be avoided if wannabe dog keepers reflected better before deciding to obtain a specific dog. Attempting to influence this decision, however, assumes that we know what the right choice is. In this chapter, we discuss three cases: pups with pedigrees, pups without pedigrees, and adult dogs from (foreign) shelters. We show that, in each case, certain moral assumptions are made whose legitimacy can be problematised. We conclude that the decision about what dog to obtain is not a straightforward one and that it is often difficult to establish what is actually the right choice. However, we also pinpoint certain improvements that can be made to the current system and make a number of suggestions that make the right choice the easier choice. As Anthropocene conditions may lead to the domestication of an increasing number of wild species in the future, this analysis may support reflection on the ethical implications of domestication.
\end{abstract}

Terms like keeper and owner of animals are controversial with respect to the autonomy of animals. We deem keeper to be more neutral than owner. As we discuss the role of people in their desire to keep a dog in their life, we choose to use this term in this chapter. Owner is used only in the term ownership for lack of a suitable replacement. Although human companion might be a better term, it might give rise to confusion as we are focusing on the moment at which a human decides to obtain a certain dog.

\author{
S. Ophorst $(\bowtie)$ \\ University of Applied Sciences Van Hall Larenstein, Leeuwarden, The Netherlands \\ e-mail: susan.ophorst@hvhl.nl \\ B. Bovenkerk \\ Wageningen University and Research, Wageningen, The Netherlands \\ e-mail: bernice.bovenkerk@wur.nl \\ S. Ophorst \\ Radboud University, Institute for Science in Society, Nijmegen, The Netherlands
}

(C) The Author(s) 2021

B. Bovenkerk and J. Keulartz (eds.), Animals in Our Midst: The Challenges

of Co-existing with Animals in the Anthropocene, The International Library

of Environmental, Agricultural and Food Ethics 33,

https://doi.org/10.1007/978-3-030-63523-7_14 


\subsection{Introduction}

As dogs are one of the most successfully domesticated species over the longest period of time, they are the quintessential example of the Anthropocenic animal. A long period of mutual influence has provided us with a lot of experience and knowledge regarding dogs; we could even say that humans and dogs have been domesticated alongside each other. From living side by side for mutual benefit in hunting and protection, to modern-day circumstances where the dog in Western countries seems totally dependent on humans, the human-dog relationship gives rise to discussion on domestication and its boundaries. Because of their long history of domestication, dogs provide an interesting illustration of the human-animal relationship and its multiple ethical challenges in the Anthropocene. The domestication of dogs could even be regarded as a paradigm case for the challenges that human-companion animal relationships face in the Anthropocene. As argued in the introduction to this volume, changing habitats and climatic circumstances lead to formerly wild animals increasingly becoming liminal. The next-perhaps inevitable — step may be the future domestication of currently wild species (see also the chapter by Palmer in this volume). Following Swart and Keulartz (2011), we view domestication as a gradual process; most animals lie somewhere on the continuum between wild and domesticated. As criteria for domestication, we take firstly the degree to which animals have adapted to their human environment and secondly the degree to which they are dependent on it. The more animals have adapted and the more dependent they are on humans, the more domesticated they are. Their level of dependence and adaptation has consequences for their agency, although these consequences are not clear-cut. For example, animals that are very dependent but not well adapted-such as a zoo animal-are frustrated in their agency, as they have little influence over their own life but likely do feel the need to express wild behaviour. Many dogs, on the other hand, are both very dependent and very well adapted. In contrast to wild dogs and stray dogs, companion dogs usually do not have the possibility to shape their own life, as their decisions are limited about, for example, where to live with what companions and with what conspecifics to mate. On the other hand, the fact that dogs are so adaptable means that they have learnt to express their agency in different ways, and they are very capable of conveying their wishes to their keepers. It is no coincidence that recent literature on animal philosophy often focuses on the human-dog relationship (Hearne 2016; Haraway 2007); dogs' adaptability and long history of domestication have enabled communication and collaboration between humans and dogs. For these reasons, we want to reflect on the lessons that can be learned from this 'successful' domestication story.

The human-dog relationship has undergone several changes: from living side by side for mutual benefit in hunting and protection, to the breeding of dogs specifically as workers, to modern-day circumstances where in Western countries dogs are primarily kept for their company and in order to confer status. All these situations have given rise to their own moral problems, leading to discussions on the justification of domestication and its boundaries. Problems faced today, for example, include dog 
health and welfare problems due to breeding for exaggerated looks, biting incidents, zoonotic diseases as a result of the importation of dogs, and health and welfare problems as well as a lack of socialisation of dogs in illegal breeding operations. In our view, many of these problems stem from the way in which people decide what dog to obtain and could be avoided if this decision moment was influenced. Of course, more ethical problems follow once one obtains the dog. Is one allowed to spay the dog for example? What should be done when the dog becomes ill and has to undergo a costly operation? Under what circumstances is one allowed to euthanise a dog? However, these problems are not the topic of this chapter, as they do not stem from the decision moment and can therefore not be influenced in the same way.

There are 1.5 million dogs in the Netherlands. As this number has been more or less consistent over the last decade, to maintain this number of dogs in society, with an average life expectancy of 10 years, each year a decision is made 150,000 times by humans to bring a new dog into their home. Of this number of dogs, Neijenhuis and Hopster (2017) established that $65 \%$ were born in the Netherlands, of which $26 \%$ had a pedigree. Of the remaining $35 \%, 16 \%$ were imported and $19 \%$ not registered-the latter being illegal in the Netherlands, which has had a mandatory identification and registration system for dogs since 2014. Different considerations by humans lead to different choices about dogs, each giving rise to its own ethical problems.

In the following sections, we discuss these choices and relate them to views expressed by animal ethicists on dog ownership in particular or pet ownership in general. Pups with pedigrees, pups without pedigrees, and adult dogs from (foreign) shelters form the cases that feature in these sections. At the end of this chapter, we discuss what can be learned from the perspective of different choices by humans and the steps forward that can be made in the interest of both dog and human. We show that, in each case, certain moral assumptions are made whose legitimacy can be problematised. We conclude that the decision about what dog to obtain is not a straightforward one and that it is often difficult to establish what is actually the right choice. This is important to realise, because if many of the problems that we encounter with dogs originate from the moment of the decision to obtain a specific $\mathrm{dog}$, and if we want to somehow steer this decision moment in the right direction, we need some perspective on what that right direction is. By discussing different motivations for obtaining a specific type of dog and problematising these, we aim to make wannabe dog keepers reflect more on the implications of such a decision.

\subsection{Animal Ethicists' Views on Dog Ownership}

Numerous animal ethicists have engaged in the discussion regarding problematic aspects of dogs as companion animals. The ideas of a number of influential scholars are used in this chapter to show the variety of ideas on this topic. What they all share is that they have a view on animal welfare. In nearly all animal ethics theories, the central idea is that we should not harm animal welfare and that we should promote positive animal welfare. However, ethicists from different theoretical backgrounds 
may hold different views on what welfare entails. For example, some define welfare as having pleasant affective states, others focus on the ability of an animal to carry out species-specific or natural behaviour, and yet others hold a broad view of welfare as well-being over the course of the animal's whole life (see Bovenkerk and Meijboom 2013). Moreover, the significance that is attached to welfare differs between different theoretical frameworks. For example-generally speaking-for welfarists, the only criterion to determine correct treatment of animals is the effects on their welfare, whereas Kantians also take considerations beyond welfare into account, and ecocentrists contend that a certain amount of suffering is simply part of an animal's life. This implies that, if a good decision about obtaining a dog is dependent at least partly on dog welfare, determining the right decision will be dependent on what moral theory one holds and how one defines welfare.

Utilitarian philosopher Peter Singer (1973) sees no problem about keeping dogs as companion animals as such, as long as suffering is avoided. He does not differentiate between domesticated and wild animals; all animals have an equal interest in experiencing enjoyment and avoiding suffering. This obligates the keepers of dogs to treat them well and prevent them from being harmed. In contrast, legal scholar Gary Francione (and Garner 2010) thinks that pet keeping in general is problematic, as it depends on the idea that pets are human property. The assertion that pets are property suggests that they are things and condemns them to being mistreated, but animals are clearly not things. As animals have moral and legal rights in his view, and beings with rights should, most fundamentally, not be treated as human property, we should not keep pets. In this view, the purposeful breeding of puppies should be abolished, and with that the practice of keeping dogs as companion animals will die out eventually. In the meantime, we should only adopt dogs from shelters and treat them as equal companions rather than 'slaves'. Francione is opposed to domestication as this violates animal rights and makes animals thoroughly dependent on humans. Domesticated animals 'are dependent on us for everything that is important in their lives: when and whether they eat or drink, when and where they sleep or relieve themselves, whether they get any affection or exercise' (Francione 2012). This view contrasts with the idea of scholars such as Stephen Budiansky (1992) and Baird Callicott (1992) that domesticated animals have hypothetically signed an unspoken 'domestication contract'. In Budiansky's view, dogs initiated their own domestication; by choosing to associate with humans, they have gained many benefits and this has given them an enormous evolutionary advantage. However, both Budiansky and Callicott argue that, when animals in a specific situation are made worse off than they would have been in the wild, or when the relationship between humans and animals has been undermined by maltreatment, the contract has been broken by humans and a domestication contract can no longer serve to justify these practices. They think that this is the case mainly in relation to the way in which livestock are raised and do not appear to have a problem with the domestication of dogs. Clare Palmer (1997), on the other hand, rejects the notion of a domestication contract, as a contract presupposes informed consent, which is something that animals cannot give. Moreover, even if the ancestors of currently living animals had voluntarily entered into a domestication contract, this cannot be assumed to still hold to this day. 
In Palmer's view (2010; Sandøe et al. 2015) then, we cannot justify our treatment of domesticated animals by assuming a domestication contract. The fact that we have domesticated animals gives rise to special obligations towards them. According to her contextual-relational ethics, there is a difference in humans' duties towards domesticated as compared to wild animals. Whereas a laissez-faire attitude towards wild animals is warranted, we have special obligations towards companion animals, livestock, or laboratory animals, because we have brought them into the situation in which they find themselves and they are dependent on us for their well-being. In fact, by domesticating them, we determine not only their freedom of movement and possibilities to make decisions for themselves, but even their genetic make-up. These actions of ours give rise to a moral commitment to take special care of their well-being.

This commitment is further elaborated regarding dogs by Kristien Hens (2009), who also argues from a relational-ethical perspective. She views the human-dog relationship as a reciprocal one; a relationship that is enabled by the fact that both human and dog are social animals. She argues, in contrast to Francione, that dogs are not treated as things or tools: 'It is questionable whether the relationship dog-human would have been so successful if they were merely man's tools.... it is more than just one of master versus slave' (Hens 2009, 6). Therefore, 'if we want to think of a proper ethic towards dogs, we must do so in the context of the dog and its specific niche, which is the human world, not using some vision of the dog as a wild animal' (Hens 2009, 5). Because dogs are 'natureculture' animals and we have decided to have a relationship with them and take them into our homes and families and in effect make them part of our communities, we have additional responsibilities towards them over and above our general responsibilities towards all sentient animals. Not only does she deem caring for the emotional and physical welfare of dogs as the responsibility of humans, but also sees special responsibilities, such as 'ensuring a bond of trust, which should not easily be broken' as part of the commitment (Hens 2009, 3). Dogs in her view, then, have an interest in maintaining a good relationship with humans and in being part of the human community. Special obligations to which this gives rise include, for example, the creation of dog parks, teaching schoolchildren how to handle dogs, and having strict government regulations on breeding. ${ }^{1}$ The special obligations also extend to the moment of choice to obtain a particular dog; in Hens' view, this should be done only after thorough reflection. Moreover, simply taking a dog to a shelter before the holiday season would violate the relation of trust between dog and human.

Sue Donaldson and Will Kymlicka (2011) give a political turn to this relational and rights-based ethic: domestic dogs should be seen as individual agents with basic rights and citizenship rights, as they are already part of our society. As we brought them into our world by domesticating them, we owe them full inclusion as it is just as much their world as ours. Contrary to Francione, these authors do not see

\footnotetext{
${ }^{1}$ Despite the focus on special responsibilities towards dogs on the basis of their place in the family and mixed community, she argues that there are limits to these responsibilities: we do not have the same responsibilities towards dogs as towards our children for example.
} 
the dependency of domesticated animals as necessarily undignified; for them, what matters is how we respond to dependency. Dependency should not necessarily be regarded as a weakness, but as a basis for a good relationship: 'If we don't view dependency as intrinsically undignified, we will see the dog as a capable individual who knows what he wants and how to communicate in order to get it - as someone who has the potential for agency, preferences, and choice' (Donaldson and Kymlicka 2011, 84). Different individuals in the human-animal relationship should be able to realise their own versions of the good life, and this means that dogs should be given the opportunity to make important choices for themselves. Such a choice could also mean that a dog no longer wants to live with a human family. The good life for a specific dog could be to become a stray dog and find a new pack outside a human family.

Finally, the good life is also central in Martha Nussbaum's capabilities approach (2006). According to this approach, justice demands that each individual is treated with respect for his/her dignity and flourishing. Each individual has certain innate capabilities and the good resides in the opportunity that the individual has to utilise those capabilities, as this is what makes the individual flourish. In order to find out what constitutes flourishing for an individual, one must create the opportunities for the individual to live up to his/her species norm. As dogs have co-evolved with humans for millennia, their species norm is different from that of wild dogs or wolves; a flourishing life for them entails their having possibilities for choice and for cultivating their capabilities, and this means that they need to be trained and disciplined to a certain extent by human guardians, just like human children. Just like Donaldson and Kymlicka, Nussbaum extends her theory of justice to the political realm. Although not giving a definite list, she suggests a number of capabilities that must be respected for animals to be able to flourish and that lead to political principles. Life and bodily health are obvious capabilities that must be met. Furthermore, she argues that, in the capabilities approach, animals are entitled to bodily integrity. For example, their bodies should not be 'mutilated' out of aesthetic motivations (Nussbaum 2006, 395). To the extent that they are capable of it, animals are entitled to make their own choices, receive suitable education or training, play, have room to move around, and have access to a variety of activities. They should also be able to form attachments to, and express love and care for, human or non-human others. Legally, animals should be granted political rights and the legal status of beings with dignity (Nussbaum 2006, 399). Finally, they have the right to the integrity of their habitat, either wild or domestic.

Against the background of animal ethics theories regarding domesticated animals, and dog keeping in particular, we next look at different practices in which dogs are obtained and point out a number of challenges in each case. We first discuss pups with pedigrees, then pups without pedigrees, and finally adult dogs from (foreign) shelters. 


\subsection{Pedigree Pups}

As people who choose to bring a pup with a pedigree into their home often use the pedigree to legitimise the consciousness and the deliberation of their decision (Bovenkerk and Nijland 2017), we start with an explanation of what a dog pedigree entails. The Fédération Cynologique Internationale (FCI) is an international organisation consisting of members and contract partners in 94 countries, with one organisation per country being allowed to join. It recognises 346 breeds, which are all assigned to countries, mostly based on heritage, which are responsible for drawing up a standard for the characteristics that the breed should have, in terms of appearance, movement, and behaviour. A pedigree is a document that proves that the breed to which the dog belongs has a certain heritage, consisting of pedigree dogs from the same breed. In the Netherlands, this entails DNA testing for all pedigree dogs to verify that the pedigree is correct. Members (kennel clubs) can attach conditions to a pedigree, but this is not obligatory. In the Netherlands, requirements for a pedigree are based on the general welfare of the brood bitch, e.g. the age of her first and last litter and the time needed between consecutive litters. For just a few breeds, there are specific requirements in terms of health, without which a dog cannot receive a pedigree. The majority of breeds do not have such requirements however.

What ethical considerations play a role in the case of pedigree dogs? As Francione wishes to abolish dogs as property, a pedigree dog is certainly not an option for him, as the pedigree is proof of heritage, but also a registration of ownership. One of the rights of dogs that can be seen as violated in pedigree dog breeding is the right to choose their own mate for propagation. In most instances, the dog and the bitch are put together by humans, often without at least the bitch having much say in the matter and being held during the act. An analogy can be made with the purposeful breeding for predictability in offspring and genetic screening in humans, which are subject to ethical and legal discussion. When it comes to embryo selection, Dutch society struggles with the topic (De Haan et al. 2010). Dutch legislation condones embryo selection for the benefit of the embryo itself. This makes it possible to screen for invasive genetic diseases and to abort the embryo if it carries such a disease. It is prohibited, however, if anyone else is the beneficiary, such as a sibling who could benefit from stem cells of the embryo to fight his/her own disease, or parents with certain wishes with regard to their progeny. Grey areas arise where multiple parties benefit. If we transfer this stance to dog breeding, the rule should be that selection in dogs should only be done if the dog is the direct beneficiary of the practice. As the dog stands to gain nothing by being the best hunter, the fastest, or the best example of the breed standard, and this is for the most part just beneficial to humans, the practice of dog breeding certainly is not in accordance with rights that are similar to those of humans. This is where Donaldson and Kymlicka (2011) also have problems with the practice of pedigree dog breeding. For them, it is very important that animals can exhibit their own agency, and this includes being able to decide themselves with whom to mate. For Nussbaum, presumably such breeding would be allowed only if it respected dogs' capabilities and led to their flourishing. This may be the case if the 
selective breeding is carried out to enhance a dog's capabilities-for example when negative side-effects of prior breeding decisions are reversed—but not for harmful aesthetic reasons.

As Singer, Hens, and Palmer emphasise humans' responsibilities towards dogs, albeit to different degrees and for different reasons, another subject for discussion is the necessity to keep dogs safe and prevent them from harm. As the issue of pedigrees in the Netherlands depends on certain rules regarding the well-being of the brood bitch, pedigrees can be said to contribute to the safekeeping of dogs.

To obtain a pedigree, a dog must stem from parents from the same breed. This limits the possibilities of propagation. Not only is the dog's freedom to choose a mate for propagation limited by this practice, but pedigree breeding also increases the risk of hereditary diseases, which can be caused by breeding in a limited gene pool.

As some of these diseases, such as heart conditions, cancer, hip dysplasia, or epilepsy, cause suffering throughout the dog's life or shorten its life expectancy, dogs are not protected from harm in these instances.

On the other hand, pedigrees can be used to prevent hereditary diseases. A pedigree is a registration, which can also be used in health testing of dogs. The test results are connected to the pedigree of the tested dog and can then be traced back in a database. As some diseases are breed specific, DNA tests for certain conditions can vary for different breeds and therefore the ancestry of the dog is relevant. By using the information from these databases and checking for genetic closeness, choices in breeding can be made that diminish the risk of hereditary diseases. The pedigree in itself is not a guarantee of this, but the use that the breeder makes of possibilities to prevent the pups being harmed determines whether this goal is met. In other words, depending on how breeders and kennel clubs use their pedigrees, the registration system can be used either to guarantee healthy dogs or have harmful effects.

The standards for each breed are the guidelines for dog-show judges to assess the dogs. Also, breeders' interpretations of these standards play a part in how these guidelines work out in actual dogs. This has led to alterations in the appearance of many breeds over the years (McGreevy and Nicholas 1999), with the exaggeration of certain traits causing health and welfare problems to the dogs. Examples of this include an emphasis on broad chests, which cause problems with movement and with natural delivery, or problems in breathing for brachycephalic dogs, such as French Bulldogs. In these instances, surely harm is done to dogs, and the dogs' interests are not protected by dog-show judges, breeders, and buyers. ${ }^{2}$ These excesses in dog breeding have given rise to an ongoing moral debate about where we should draw the line when changing the genetic make-up of companion animals, analogous to the debate that has been going on about selective breeding and genetic modification in livestock. This debate has focused not only on resulting health and welfare problems,

\footnotetext{
${ }^{2}$ However, it is not so easy to use ethical theory to explain why harm is done to these dogs, as the changes to the dogs have been made before the dogs were born and therefore one cannot say that a particular individual has been harmed. For a discussion on this application of the so-called non-identity problem to dogs, see Palmer (2012) and Bovenkerk and Nijland (2017).
} 
but also on other ethical concerns. For example, some argue that extreme breeding violates dogs' integrity, that it objectifies or commodifies dogs, or that it is unnatural (Bovenkerk and Nijland 2017). On the other hand, a recent Danish study (Sandøe et al. 2017) shows that keepers of some breeds find that the problems that their dogs encounter are actually a reason for their strong bond, probably because the dog needs so much care and attention. Hens, in particular, emphasises the importance of the bond between dogs and their keepers. She probably assumes that this bond will primarily have advantages for the dog. The tension between dog welfare and the strong bond-as experienced by humans-in this situation establishes that this is not necessarily the case.

Historically, dogs were selected for function (e.g. hunting, guarding) and the dog's appearance merely needed to support this function. With large parts of these functions being taken over by newer developments (such as the meat industry and security cameras), the focus has shifted from function to appearance (Lindblad-Toh et al. 2005). This does not mean that all behavioural traits have vanished, as they are still present in the dogs today. It is a shift from an emphasis on function, with the best hunting dog being the most wanted, to appearance, where the dog that best looks the part is most popular in breeding. This entails a risk of humans choosing a certain breed, based mainly on appearance, without realising that the original function of the dogs requires them to roam around freely for hours on end, hunt other animals, be aware of others (including humans) entering their domain-needs that cannot necessarily be met in a dog's everyday life in the Netherlands.

As the information on the dog's heritage is guaranteed by the pedigree, this also contributes to the predictability of the dog's behaviour. It is sometimes argued that people have a better chance of finding a dog that is compatible with their circumstances when they choose a pedigree pup than it is when they choose a pup without a pedigree. ${ }^{3}$ However, as the information in breed standards on behaviour is very limited-e.g. 15 of the 434 words in the Golden Retriever standard (FCI 2009) one could question whether people can rely on this information. Obviously, more information is needed to evaluate compatibility. Breeders may be able to provide this information, as they are knowledgeable about the breed, at least as an experiential expert, but are not required to do so in order to be able to sell puppies with pedigrees.

As dogs with pedigrees are more expensive than dogs without pedigrees, there is a chance that the motive to make money will override informing prospective buyers on subjects that would possibly prevent them from buying a puppy of a certain breed. Singer would argue on this subject that humans' differing interests must be weighed against each other (earning a living versus living with a suitable dog) and this then must also be weighed against the interest of the dog (living in conditions where not all the dog's needs are met). The outcome of this weighing is not clear-cut. For Hens, the possible endangerment of the formation of a bond of trust between human and dog by withholding information weighs heavily, and she therefore condemns practices that put financial benefits before the human-dog bond. Palmer draws a line between commercial and non-commercial dog breeding, with pedigree breeders falling into

\footnotetext{
${ }^{3}$ Based on interviews carried out by Bernice Bovenkerk and Hanneke Nijland in 2015 and 2016.
} 
the category of non-commercial breeding most of the time, because of the limited number of litters that they are allowed to produce in order to obtain a pedigree for the dogs. The commercial aspect in itself does not seem to cause her concern, but the emphasis on profit over animal welfare does.

If we look at the ethical acquirement of a dog and deem it most important to prevent harm to the dog, obtaining a pedigree dog does not have to be ruled out. On the other hand, pedigree dog breeding does not necessarily support the ethical acquirement of dogs either. The full potential of pedigrees to contribute to the wellbeing of dogs is currently not met. If the pedigree served more than is currently the case as a quality mark for adhering to dog welfare, testing on hereditary diseases, and informing prospective buyers, more problems in the breeding and keeping of pedigree dogs could be overcome. It is, however, important for wannabe dog keepers to realise that the pedigree at the moment is not in all cases a mark of good dog welfare.

\subsection{Pups Without Pedigree}

As only a relatively small proportion of the dogs acquired in the Netherlands have a pedigree, it is also interesting to look at pups without a pedigree. Maybe they will turn out to be the more ethical choice when people want to share their life with a dog.

Pups without pedigrees can be dogs from a breed that is not registered with the FCI and therefore not entitled to a pedigree. These dogs can have the advantages of a pedigree dog with regard to the predictability of, for example, size and personality as an adult, but registration does not even have the basic requirements that a pedigree has. One is therefore dependent on the reliability of the breeder. Mostly, these are breeds created by selection not so long ago. Examples of these new breeds or designer breeds are the Labradoodle and the Miniature Australian Shepherd, but the Pitbull also has no FCI registration. The problems encountered with pedigree dogs may also exist with this type of dog and maybe even more so as the trustworthiness of the registration papers is more questionable. Although the latter is debatable, as the Dutch Kennel Club is not monitored by the Dutch government either, at least procedures have for long been in place regarding self-control and upholding the rules.

Pups without pedigrees can also be pups from pedigree dogs, where the breeder did not apply for a pedigree. In most instances, a pedigree being too expensive and people not wanting to 'pay for a piece of paper' is given as the reason for not applying for the pedigree. It cannot be ruled out, however, that an important reason may also be to avoid the minimal requirements of a pedigree in terms of dog welfare. As in this case dogs' heritage is not confirmed by a pedigree, one can also question whether other breeds or untraceable dogs are in the ancestry of the pups. Dogs that look very similar to pedigree dogs but do not actually have a pedigree are called look-alikes. As these dogs are bred from the same gene pool as the pedigree dogs, most geneticsrelated problems in pedigree dogs will also be found in look-alikes. One could argue 
that the lack of testing and information on problems in certain lines of a breed might even enhance the problem. A study by Van Zeeland and Beerda (2015) showed that it is impossible to determine whether problems are more severe in dogs with pedigrees or in look-alikes, because of the lack of registration of pedigrees by veterinarians and the lack of control on the reports by dog keepers, who consider the dog to be a pedigree dog even if the dog does not actually have a pedigree. From the perspective of people acquiring these puppies, the money argument is mostly used to warrant this choice. There are people that find it ridiculous to spend a lot of money on a dog. Although the money transaction is proof of the dog being considered property and therefore not regarded as an ethical choice according to Francione, there is not much difference between paying a large and a small amount of money. As caring properly for a dog also involves at least feeding and veterinary costs, one can argue that not being willing to spend money on the 'purchase' of a puppy does not bode well for the intentions towards proper care of the dog after the puppy has entered the household, which can also be costly. As people tend to be more involved with a purchase when it involves a larger amount of money (Bauer et al. 2006), one could argue that a lower price for a dog can have a negative effect on the considerations made before getting a dog. A large number of the puppies in this category are distributed through illegal dog traffickers and so-called puppy mills, which are notorious for the deplorable state in which bitches and puppies are kept, with diseases and even premature death as a result (Radstake 2016). Here, certainly, people's responsibility towards dogs is not honoured and dogs suffer; this makes these practices reprehensible in the eyes of all animal ethicists.

Then there are the pups that look like originals, whose background can only be guessed. These are the dogs that are commonly referred to as mutts or mongrels. Despite these not very flattering names, positive traits are attributed to these dogs as they are said to be strong and healthy, often in comparison to pedigree dogs (Patronek et al. 1997). As a longer life expectancy in combination with fewer health problems is in the interest of the dog, this might be a preferred choice when a person is obtaining a puppy. As dogs nowadays are not normally free-ranging animals in the Netherlands, with rules for keeping dogs on the leash in most areas, dogs have little chance of meeting a mate without their keepers' interference. In the old days, dogs would just roam to nearby farms when there was a bitch in heat, but these 'accidental litters' from a human perspective-are rare these days. In Kymlicka and Donaldson's work, the fact that humans make the procreative choices for dogs is already problematic. Keeping dogs on leashes can, however, also be seen as an instrument to keep dogs safe. In densely populated countries like the Netherlands, many more dogs would fall victim to traffic accidents if they had more freedom. Also, other animals would be at risk from dogs hunting.

With lots of dogs being castrated, especially when dogs and bitches are kept in the same household, there is an increasingly small chance of dogs in the same household procreating. The number of puppies born out of free encounters between dogs is not registered, but it is surely nowhere near the number needed to fulfil the demand for companion dogs. Then there are the encounters between dogs that are put together by their keepers. There are few such deliberate non-pedigree litters, although 
they might solve some problems that arise with pedigree dogs. In 2017, a Dutch foundation, Dier \& Recht (Animals \& the Law), known for lawsuits against pedigree dog breeders, launched an initiative called Cupidog. Cupidog aims to bring healthy dogs and bitches of different breeds or unknown descent together to create healthy puppies that are brought up under good conditions. Amongst the candidate dogs on the Cupidog website are dogs that are obviously of breeds that carry major problems. Cupidog aims for healthy puppies by ensuring that a dog will never be mated to a dog comprised of $50 \%$ or more of the same breed and by having every combination approved by a committee of two veterinarians. Interestingly, the majority of dogs enrolled in this service are male. The similarity with dating services for humans is remarkable, as male clients also predominate on those dating websites. In the case of Cupidog, obviously the dog does not choose to be put on the website, and no information is provided on the sex of the dog's keeper. It might be interesting to investigate the extent to which idealised online identities are portrayed of the dogs on Cupidog, as is found to be the case with human dating sites (Hancock et al. 2007). In the Cupidog case, a reason for the overrepresentation of males might be that the female dogs' keepers are expected to care for the puppies and might also take into account the risk for their bitch in delivering a litter, whereas the male dogs' keepers might see their dog as a great candidate to produce offspring or want to cater to their dog's sexual urges. For the keepers of male dogs, Cupidog involves no risk or work for the human and therefore might be an easier choice.

Although the health of mongrel dogs is used as a reason to favour these dogs when a puppy is being chosen, it cannot be ruled out that the low purchase cost of these dogs is also relevant to dog buyers. Cupidog sets the price for pups from litters that they mediate at between $€ 500$ and $€ 700$. This is lower than for most pedigree dogs, but higher than for dogs from a shelter or what people are used to paying for a non-pedigree dog. This might be another reason-besides the lack of potential mother dogs-why this initiative is not taking off with a flying start. As in the case of look-alikes, it is not very promising if humans are not willing to pay these prices when the costs of keeping a dog are much higher than the purchase cost and it may mean people pay less attention to the decision of getting a dog (Bauer et al. 2006).

Another aspect of mongrel pups is the uncertainty about what they will grow into. Pedigrees provide an estimation of the character and size of the dog, as also is largely the case with non-official breeds and look-alikes, but a mongrel dog can easily surprise one. This might lead to an adult dog that does not suit one's situation, and this can be detrimental to the welfare of both dog and human. From Hens' perspective, in these instances the dog should remain in the situation, as the bond between dog and keeper should be respected and preserved at all times. It can, however, be argued that it is not in the dog's best interest to be kept in inappropriate circumstances. This predicament is caused by the unpredictability of how a puppy will turn out as a mature dog. Although mongrel dogs, then, give people less control over the outcome, it could be argued in their favour that the need of humans to be in control over and 'manufacture' nature is in itself wrong and should not be encouraged (Bovenkerk and Nijland 2017). Dogs could, however, be the victim of mismatches and not in a position to alter their circumstances as their keepers might be. Responsibility in 
Palmer's terms is a leading concept here. The dog's best interest should prevail in these situations and guide decisions on the dog's future.

In sum, acquiring a dog without a pedigree is, again, not necessarily a good or a bad choice. On the other hand, there is no ethically sound argument for purchasing a dog that stems from illegal dog trafficking or a puppy mill. This pleads for stronger regulations and enforcement of these regulations to ensure (breeding) dogs' welfare and discourage current practices. The option of obtaining a dog this way is simply a bad choice. This is not necessarily the case for non-pedigree look-alikes or new breeds. Here, the same arguments hold as previously put forward for the pedigree dogs: a registration system could be used to enhance dog welfare and eliminate some of the problems encountered in dog breeding. On the basis of ethical arguments, the original dogs are a promising choice, as long as they can be distinguished from pups from puppy mills or illegal dog trafficking. Favouring this option is not, however, carefree either. Considerations about possibilities to match the demand with the offer while still guarding the boundaries of welfare and dog rights are challenging. Creating awareness of the costs of dog keeping and the expectations regarding the dog will prove to be just as challenging.

\subsection{Shelter Dogs}

Most dogs mediated by animal shelters are adults. Sometimes, a pregnant bitch is brought into a shelter and delivers her pups there or in a foster home. Sometimes, puppies are found as strays and brought to animal shelters. Sometimes, puppies are confiscated from puppy traffickers and taken in by shelters. The majority of confiscated, stray, and relinquished dogs, however, are adult.

As taking in a shelter dog does not require deliberately bringing new dogs into the world, it is a practice that Francione condones as the proper solution for fading out the practice of keeping dogs as property. Most shelters do not offer the opportunity to buy a dog, just to adopt. This may be seen as an option to avoid the 'dogs as property issue'. Unfortunately, there still remains an 'owner', which in the case of shelter dogs is the shelter itself, even if the dogs are adopted out. One could argue that the possibility of putting dogs into shelters makes it easier for people to carelessly buy new dogs and therefore perpetuates this situation. In Francione's vision, it should be prohibited to keep dogs, and getting a dog from a shelter would be just a temporary solution for dogs that have already been brought into this world. Even though in Hens' view it is morally problematic to take a dog to a shelter, she also prefers people obtaining their dogs from shelters over breeding, in particular purebred dogs. She suggests that shelters should employ dog behaviourists in order to match the right dog to the right person (Hens 2009).

People who want a dog from a shelter can be motivated by a number of reasons: wanting to save a dog in need, to save money as shelter dogs are less costly to obtain than most puppies, wanting an older dog that is already housebroken, obedient, or calmer, or wanting an adult dog to avoid a mismatch. Dogs' welfare is an argument 
for people wanting to save dogs from the shelter and could also be an argument for people wanting to avoid a mismatch, as mismatches can be the source of welfare problems.

The current situation in Dutch shelters shows that the 'save the dog argument' is not particularly strong as an exclusive argument. This would entail people choosing to adopt the dogs that are most unhappy in the shelter situation or have been there for the longest time. Instead, people leave the long-stay dogs in the shelter, as the smaller and younger dogs or dogs of popular breeds get out of the shelter more quickly (Dierenbescherming 2018).

The 'saving argument', then, does not seem to be the decisive argument for a lot of people.

It could also be that people whose priority is to save dogs choose to get a dog from a foreign, mostly South or Eastern European, shelter. In the Netherlands, this has become a common option that has been growing in recent years (Radstake 2016). A reason given for choosing a foreign versus a Dutch shelter is the situation within these shelters. As Dutch shelters are mostly governed by the Dutch Society for the Protection of Animals (Dierenbescherming), basic welfare for dogs in the shelters is guaranteed, and euthanasia of shelter dogs is not common practice and is carried out only in very specific circumstances. In countries like Spain and Greece, shelters are mostly private initiatives run on tight budgets and have to provide shelter for too many dogs, leading to deplorable situations. Originally, tourists brought back stray dogs and shelter dogs from their holidays, but nowadays 130 organisations mediate between foreign shelters and Dutch people looking for a dog (Radstake 2016). As the willingness to save dogs is given as an important motivation for adopting a dog from abroad, it is important to take a closer look at this situation.

The main problems with foreign shelter dogs seem to be their lack of socialisation and potential health risks (Buckley 2020). As the Mediterranean countries have a different climate, different diseases exist there, for example because they are hosted by parasites that thrive on those weather conditions. Brucellosis and rabies are examples of zoonotic diseases that can be transferred from dogs to other dogs and to humans. Blood testing before adoption can help to prevent problems, but not all diseases can be tested for definitively, and some have long incubation times, which may lead to false-negative results (Fox et al. 1986). So far, no large outbreaks of diseases brought into the country by foreign shelter dogs have been reported, but, with the increasing number of this type of dog entering the country, this could quite easily happen. Besides the health risks for Dutch dogs, therefore also risks for Dutch people must be taken into account; dogs from foreign shelters form a potential public health risk.

It is not always easy to distinguish the origin of the dog. Cases are known of Dutch shelters bringing in dogs from foreign shelters to meet the demand for smaller and younger dogs (de Joode, n.d.). Instances have also been reported of organisations with just a commercial motive pretending to save foreign shelter dogs (Van Niekerk et al. 2014). These organisations play into the positive dog-saving image of the legitimate rescue organisations, when their practice is actually plain dog trafficking, often also without proper procedures followed and health precautions taken. People 
are therefore advised to check dogs' vaccinations, microchips, and the organisation's legitimacy. This requires extra action on the part of wannabe dog keepers, and it is uncertain to what extent they will actually follow this advice when the easy option is to fall in love with a sweet dog or give into the urge to save an innocent animal from life on the street or from a terrible shelter.

Many of the dogs in foreign shelters have led stray dog lives before being sheltered. This means that they are not used to living in a house, are used to lots of freedom to roam around, are used to being on the constant lookout for food, are wary of humans, and so on (Pal et al. 1998; Udell et al. 2010). Looking at this situation from a human point of view, the dogs might be suffering in these circumstances, with hunger, danger, and illnesses always lurking. This would require action on welfare grounds according to Singer and, in the case of abandoned dogs, also to Palmer. From Donaldson and Kymlicka's perspective, domesticated dogs have the right to food, shelter, and medical care. But what should be done about dogs' right to make their own decisions, to freedom, and to execute their agency? One could argue that the freedom that these free-ranging dogs enjoy is of great value (Majumbder et al. 2014; Paul et al. 2016) and is at risk when they are adopted out to the Netherlands. Dutch society is totally different than what the dogs are used to, and dogs that are adopted in the Netherlands out of such different circumstances certainly lose freedom and can have behavioural problems (Dietz et al. 2018). Moreover, the capabilities and interests of dogs that have formed attachments to other stray dogs and perhaps formed packs with them are not respected when they are suddenly taken out of their environment. In Nussbaum's view, this could be problematic, because capabilities are at least partly formed by one's relationships. This situation can cause a lot of anxiety in dogs that is by no means beneficial to their welfare or flourishing. On the other hand, in contrast to Donaldson and Kymlicka, Nussbaum does not distinguish clearly between domesticated dogs, who are part of our communities, and wild or stray dogs, who for Donaldson and Kymlicka have the right to have their sovereign communities respected. Nussbaum would be less hesitant to take in stray or wild dogs, as long as this does not interfere with their flourishing. Despite good intentions and professional help, however, there is often little that can be done to correct for the dog's bad or different start, as dogs' socialisation period ends at around four months of age (Freedman et al. 1961).

One might argue that there are similarities between adopting dogs and adopting children from other countries. Problems with attachment and adjustment have also been said to be issues in the adoption of children from other countries (Post 2008). However, there have also been reports to the contrary, as most children show a lot of resilience and the effect of growing up in poor circumstances may be even more negative (Juffer 2008). As the socialisation of dogs and humans differs and the 'window' for dogs to be socialised closes at an early age (Serpell and Jagoe 1995), the analogy between human and dog fails in this respect. Still, in the last decades, the view on adopting children from foreign countries has changed. Whereas saving children from detrimental circumstances was considered a noble action not so long ago, the current vision is that problems with human trafficking are prevalent in adoption procedures (Post 2008). Because of this, there is a tendency to leave children in 
the area from which they originate and provide care there. Obviously, this does not solve the desire for children of people who are unable to conceive children, but the children's welfare should take priority, and this has led to a decreasing number of children from other parts of the world being adopted in the Netherlands (Slot 2008). This can be compared to dogs, because, in the case of importing foreign shelter dogs, there is also mention of dog traffickers profiting from the transaction (Stray Animal Foundation Platform 2018). It would be beneficial to the dogs to remain in their country of origin and receive help there to ensure better living conditions for them. If anyone wanting to adopt a foreign dog did so without actually bringing the dog to the Netherlands and just supported it financially throughout its life, it would certainly make a contribution to the dog's welfare.

Adopting a dog from either a Dutch or a foreign shelter can be a better choice if prospective adopters look carefully into the organisation providing these dogs. Clear rules and quality characteristics are not easily found by the wannabe dog keeper, so improvements are necessary. Determining the suitability of the dog for the adopter's situation is another topic that can be easily trivialised and should receive more attention.

\subsection{Discussion}

As we have seen, ethical challenges exist in every choice when a dog is being obtained. As we define a good choice as a choice where at least the welfare of the dog is served and the welfare of other dogs and animals (including humans) is not harmed, one can wonder whether there is such a thing as a good choice of dogs. In Francione's view, abolishing altogether the practice of keeping dogs is the only option. The other animal ethicists that we discussed are less dismissive of the domestication process as such and the opportunities for dogs to experience good welfare or to flourish, although different ethicists use different definitions of welfare, and in practice these opportunities often fail to materialise.

However, all three channels/scenarios discussed provide options to better protect the welfare of all concerned. In the current situation, there is ample room for improvement in the dog-breeding system, with its forced mating, harmful breed characteristics, and restricted gene pools. On the part of the people wanting a dog, this entails careful consideration to determine what is in the best interest of all involved. This requires self-control at the moment of decision making about a specific dog. As Berkman et al. (2017) show, self-control is a value-based decision-making process in which people weigh up different aspects. In this process, easy choices are given more weight than difficult ones. Factors like the time it takes to acquire information, the effort it takes to process the information, or the financial costs can be barriers to making right decisions. Currently, agencies that want to improve decision making regarding dogs put a lot of emphasis on information that people should acquire before making their decision about a dog. With such an overload of information, it is not strange that people fall victim too easily to processing arguments such as nice 
memories of the dogs they used to have, the example of the dog next door, or a cute appearance.

Solutions can be found in multiple directions. One direction is the possibility of governmental control, possibly delegated to neutral controllers, on for example pedigrees and shelter licences (including more stringent breeding standards towards better health and welfare), an obligatory waiting period to enable people to do their research before bringing a dog home (which is currently standard practice in many Dutch shelters), or even the obligation to obtain a licence before being allowed to obtain and keep a dog. In a study by Packer et al. (2017) on the purchase of pedigree dogs, over a third of the respondents testified that they would do more prepurchase research the next time they wanted to purchase a dog. Another direction is the possibility of different sectoral organisations implementing these measures. This has proved difficult, with sectoral organisations being dependent on support from their members, who may have different interests, resulting in slow change processes. The third direction lies in influencing wannabe dog keepers. If people are made aware of the consequences of bad decisions and are facilitated in making the right choices, this could be an essential step towards better dog welfare. As we have seen in the work of Berkman et al. (2017), the key is to make the good choice the easy choice. This requires the information to be presented in such a way that it can be easily accessed and processed by the wannabe dog keeper, and it may also entail a better infrastructure for dog acquisition practices. One could think here, for example, of making it more difficult to obtain a dog through less trusted channels, such as internet marketplaces. This is not possible for an individual to achieve without the assistance of all other parties. Moreover, it helps when wannabe dog keepers have positive role models or a social network that enables them to reflect on their decision. After all, the dog that someone has often becomes part of that person's identity, and a positive role model will help to shape an identity that matches well with the dog's welfare. An integrated approach towards sensible dog keeping is therefore the most promising route.

Humans' special responsibility towards dogs, in Palmer's and Hens' views, warrants the investment in these types of integral solutions. As dogs' welfare is served with this approach, an integral solution also complies with Singer's view. Moreover, in an integral approach, potential mismatches are avoided and guided choices are beneficial to the relationship between dog and human, as emphasised by Hens. The political solutions set out above would be supported by Donaldson and Kymlicka as well as Nussbaum.

What remains is the discussion on ownership and property. This is an issue that cannot simply be overcome by changing names or constructions such as adoption rather than ownership. Recognising that dogs cannot be seen or treated as a tool or an ornament, and therefore need advocates on their behalf, is a step on the route towards solutions that constitute a good choice, as already sketched. This seems to be the closest we can get other than abolishing companion animals altogether. After all, we can wonder how realistic the abolishment of animal domestication is. The destiny of many currently wild animals may be to become domesticated as a result of Anthropocene conditions. Human and animal habitats are becoming more and 
more intertwined, and animals are facing challenges to their survival consequent to changing climatic and environmental conditions. In order to help them survive, we may have to resort to technical and other interventions that may cause them to lose a measure of wildness (see the chapter by Palmer in this volume) and become more liminal or even domesticated. If an increasing number of animals become domesticated, we shall be facing challenges similar to the ones sketched in this chapter. Reflection on the pitfalls of dog keeping, and in particular the question of what dog to obtain, may shed some light on the challenges faced in the Anthropocene.

\section{References}

Bauer, H.H., N.E. Sauer, and C. Becker. 2006. Investigating the relationship between product involvement and consumer decision-making styles. Journal of Consumer Behaviour 5 (4): 342-354.

Berkman, E.T., C.A. Hutcherson, J.L. Livingston, L.E. Kahn, and M. Inzlicht. 2017. Self-control as value-based choice. Current Directions in Psychological Science 26 (5): 422-428.

Bovenkerk, B., and F.L.B. Meijboom. 2013. Fish welfare in aquaculture: Explicating the chain of interactions between science and ethics. Journal of Agricultural and Environmental Ethics 26 (1): 41-61.

Bovenkerk, B., and H.J. Nijland. 2017. The pedigree dog breeding debate in ethics and practice: Beyond welfare arguments. Journal of Agricultural and Environmental Ethics 30 (3): 387-412.

Buckley, L.A. 2020. Imported rescue dogs: Lack of research impedes evidence-based advice to ensure the welfare of individual dogs. Veterinary Record 186 (8): 245-247.

Budiansky, S. 1992. The Covenant of the wild: why animals chose domestication: With a new preface. London: Yale University Press.

Callicott, J.B. 1992. Animal rights and environmental ethics: Back together again. In The Animal Rights/environmental Ethics Debate: The Environmental Perspective, ed. E. Hargrove, 249-261. Albany, NY: SUNY Press.

De Haan, G., R. Benedictus, R. van Graafeiland, and M. Wissenburg. 2010. Gen-ethische grensverkenningen. Een liberale benadering van ethische kwesties in de medische biotechnologie. Report. The Hague: Teldersstichting.

de Joode, W. n.d. https://www.animalinneed.com/asiel-buitenland. Retrieved 14 March 2019.

Dierenbescherming. 2018. Jaarverslag Dierenbescherming 2017. https://www.dierenbescherming. nl/userfiles/pdf/Jaarverslagen/Jaarverslag_dierenbescherming_2017.pdf. Retrieved 8 July 2020.

Dietz, L., A.M.K. Arnold, V.C. Goerlich-Jansson, and C.M. Vinke. 2018. The importance of early life experiences for the development of behavioural disorders in domestic dogs. Behaviour 155 (2-3): 83-114.

Donaldson, S., and W. Kymlicka. 2011. Zoopolis: A political theory of animal rights. Oxford: Oxford University Press.

Federation Cynologique International (FCI). 2009. Breed standard Golden Retriever. http://www. fci.be/Nomenclature/Standards/111g08-en.pdf. Retrieved 13 March 2019.

Fox, J.C., H.E. Jordan, K.M. Kocan, T.J. George, S.T. Mullins, C.E. Barnett, and R.L. Cowell. 1986. An overview of serological tests currently available for laboratory diagnosis of parasitic infections. Veterinary Parasitology 20 (1-3): 13-29.

Francione, G. 2012. Blogpost. http://www.abolitionistapproach.com/pets-the-inherent-problemsof-domestication/\#.VkS-L-s45p.

Francione, G., and R. Garner. 2010. The animal rights debate: Abolition or regulation? New York: Columbia University Press. 
Freedman, D.G., J.A. King, and O. Elliot. 1961. Critical period in the social development of dogs. Science 133 (3457): 1016-1017.

Hancock, J.T., C. Toma, and N. Ellison. 2007, April. The truth about lying in online dating profiles. In Proceedings of the SIGCHI Conference on Human Factors in Computing Systems, 449-452.

Haraway, D. 2007. When species meet. Minneapolis, MN: University of Minnesota Press.

Hearne, V. 2016. Adam's task: Calling animals by name. New York: Skyhorse.

Hens, K. 2009. Ethical responsibilities towards dogs: An inquiry into the dog-human relationship. Journal of Agricultural and Environmental Ethics 22 (1): 3-14.

Juffer, F. 2008. De ontwikkeling van interlandelijk geadopteerden; een overzicht van onderzoek. Justitiële Verkenningen 34 (7): 38-53.

Lindblad-Toh, K., C.M. Wade, T.S. Mikkelsen, E.K. Karlsson, D.B. Jaffe, M. Kamal, et al. 2005. Genome sequence, comparative analysis and haplotype structure of the domestic dog. Nature 438 (7069): 803 .

Majumder, S.S., A. Bhadra, A. Ghosh, S. Mitra, D. Bhattacharjee, J. Chatterjee, et al. 2014. To be or not to be social: Foraging associations of free-ranging dogs in an urban ecosystem. Acta Ethologica 17 (1): 1-8.

McGreevy, P.D., and F.W. Nicholas. 1999. Some practical solutions to welfare problems in dog breeding. Animal Welfare-Potters Bar 8: 329-342.

Neijenhuis, F., and H. Hopster. 2017. Reductie van gezondheidsrisico's bij import van honden; actieve communicatie als beleidsinstrument. Wageningen Livestock Research, Internal Unpublished Livestock Research Report.

Nussbaum, M. 2006. Frontier of justice: Disability, nationality, species membership. Cambridge, MA: The Belknap Press.

Packer, R.M.A., D. Murphy, and M.J. Farnworth. 2017. Purchasing popular purebreds: Investigating the influence of breed-type on the pre-purchase motivations and behaviour of dog owners. Animal Welfare 26 (2): 191-201.

Pal, S.K., B. Ghosh, and S. Roy. 1998. Agonistic behaviour of free-ranging dogs (Canis familiaris) in relation to season, sex and age. Applied Animal Behaviour Science 59 (4): 331-348.

Palmer, C. 1997. The idea of the domesticated animal contract. Environmental Values 6 (4): 411-425.

Palmer, C. 2010. Animal ethics in context. New York: Columbia University Press.

Palmer, C. 2011. The moral relevance of the distinction between domesticated and wild animals. In Oxford handbook of animal ethics, ed. T.L. Beauchamp and R.G. Frey, 701-723. Oxford University Press.

Palmer, C. 2012. Does breeding a bulldog harm it? Breeding, ethics, and harm to animals. Animal Welfare 21 (2): 157-166.

Patronek, G.J., D.J. Waters, and L.T. Glickman. 1997. Comparative longevity of pet dogs and humans: implications for gerontology research. The Journals of Gerontology Series A: Biological Sciences and Medical Sciences 52 (3): B171-B178.

Paul, M., S.S. Majumder, S. Sau, A.K. Nandi, and A. Bhadra. 2016. High early life mortality in free-ranging dogs is largely influenced by humans. Scientific Reports 6: 19641.

Post, R. 2008. De perverse effecten van het Haags Adoptieverdrag. Justitiële Verkenningen 34 (7): $25-27$.

Radstake, C. 2016. Immigratie van buitenlandse (zwerf)honden \& (zwerf)katten naar Nederland: de cijfers 2016. Stray Animal Foundation Platform.

Sandøe, P., S. Corr, and C. Palmer. 2015. Companion animal ethics. Chichester, UK: Wiley.

Sandøe, P., S.V. Kondrup, P.C. Bennett, B. Forkman, I. Meyer, H.F. Proschowsky, et al. 2017. Why do people buy dogs with potential welfare problems related to extreme conformation and inherited disease? A representative study of Danish owners of four small dog breeds. PLOS ONE 12 (2): e0172091.

Serpell, J., and J.A. Jagoe. 1995. Early experience and the development of behaviour. In The Domestic Dog: Its evolution, behaviour and interactions with people, ed. J. Serpell, 79-102. New York: Cambridge University Press. 
Singer, P. 1973. Animal liberation. In Animal rights, ed. R. Garner, 7-18. London: Palgrave Macmillan.

Slot, B.M.J. 2008. Adoptie en welvaart; een analyse van vraag en aanbod van adoptiekinderen. Justitiële Verkenningen 34 (7): 11-24.

Stray Animal Foundation Platform. 2018. Wildgroei adopties buitenlandse honden aan banden Stichtingen slaan handen in één, September 13. Retrieved from https://www.stray-afp.org/nl/nie uws/wildgroei-adopties-buitenlandse-honden-aan-banden-stichtingen-slaan-handen-in-een.

Swart, J.A.A., and J. Keulartz. 2011. Wild animals in our backyard: A contextual approach to the intrinsic value of animals. Acta Biotheoretica 59 (2): 185-200.

Udell, M.A., N.R. Dorey, and C.D. Wynne. 2010. The performance of stray dogs (Canis familiaris) living in a shelter on human-guided object-choice tasks. Animal Behaviour 79 (3): 717-725.

Van Niekerk, T.G.C.M., P. Potters, and M. Meeusen. 2014. Rapportage kwalitatief onderzoek 'Identificatie en Registratie van honden' (no. 818). Wageningen UR Livestock Research.

Van Zeeland, C.W.M., and B. Beerda. 2015. Hereditary disorders in pedigree dogs and look-a-likes (no. 317). Wageningen UR, Science Shop.

Susan Ophorst is senior lecturer at the bachelor Animal Management of the University of Applied Sciences Van Hall Larenstein in Leeuwarden, The Netherlands, and researcher (Ph.D.) in human-animal relationships at the Institute of Science in Society of Radboud University and University of Applied Sciences Van Hall Larenstein. Her main focus is the relationship between humans and dogs in Dutch society. This chapter would not have been possible without the financial support of the Dutch Research Council (NWO). This work is part of the research programme 2017-I BOO with project number 023.010.030, which is (partly) financed by the Dutch Research Council (NWO).

Bernice Bovenkerk is associate professor of philosophy at Wageningen University, the Netherlands. Her research and teaching deals with issues in animal and environmental ethics, the ethics of climate change, and political philosophy. Current topics are animal agency, the moral status of animals and other natural entities, with a particular focus on fish and insects, the ethics of animal domestication, animal (dis)enhancement, and deliberative democracy. In 2016 she coedited (together with Jozef Keulartz) Animal Ethics in the Age of Humans. Blurring boundaries in human-animal relationships (Springer) and in 2012 she published The Biotechnology Debate. Democracy in the face of intractable disagreement (Springer). She received her Ph.D. title in political science at Melbourne University and her Master's title in environmental philosophy at the University of Amsterdam. Her homepage is bernicebovenkerk.com.

Open Access This chapter is licensed under the terms of the Creative Commons Attribution 4.0 International License (http://creativecommons.org/licenses/by/4.0/), which permits use, sharing, adaptation, distribution and reproduction in any medium or format, as long as you give appropriate credit to the original author(s) and the source, provide a link to the Creative Commons license and indicate if changes were made.

The images or other third party material in this chapter are included in the chapter's Creative Commons license, unless indicated otherwise in a credit line to the material. If material is not included in the chapter's Creative Commons license and your intended use is not permitted by statutory regulation or exceeds the permitted use, you will need to obtain permission directly from the copyright holder. 